\title{
Chemical and photoelectron spectrometry analysis of the adsorption of phospholipid model membranes and red blood cell membranes on to chrysotile fibres
}

\author{
M C JAURAND, ${ }^{1}$ J H THOMASSIN, ${ }^{2}$ P BAILLIF, ${ }^{2}$ L MAGNE, ${ }^{1}$ J C TOURAY, ${ }^{2}$ \\ AND J BIGNON ${ }^{1}$ \\ From the Laboratoire de Recherches sur les Affections Respiratoires et l'Environnement, ${ }^{1}$ \\ ERA CNRS $N^{\complement} 845$, INSERM U 139, Hôpital Henri Mondor, 94010 Créteil, and the Laboratoire de \\ Géologie, ${ }^{2}$ Géochimie et Minéralogie Appliquées, ERA CNRS $N^{\mathrm{C}} 601$, Université d'Orléans, Orléans, France
}

\begin{abstract}
A study of the interaction of phospholipid model membranes and red blood cell membranes with UICC A chrysotile fibres using chemical analysis and photoelectron spectrometry showed that the interaction agreed with an adsorption of the membranes on to the chrysotile fibres. The photoelectron spectrometry analysis allowed the statement that phospholipid model membranes are adsorbed as bilayer. Chemical analysis showed that for each milligram of chrysotile the amount of phospholipids adsorbed was about $155 \mu \mathrm{g}$ and the available surface for phospholipids was about $38 \mathrm{~m}^{2} / \mathrm{g}$. It was established that entire membranes were adsorbed. A mechanism for the haemolytic capacity of chrysotile is suggested.
\end{abstract}

Many investigations have provided information on the adsorptive capacity of asbestos fibres. ${ }^{1-4}$ Recent studies ${ }^{5}$ have shown that the surface charge of the fibres determines the haemolytic activity and that the adsorption of dipalmitoyl phosphatidyl choline (DPPC), the main component of pulmonary surfactant, reduces the surface charge. Previous studies have shown that pretreatment of chrysotile with red blood cell (RBC) membranes? ${ }^{7}$ or with phospholipids $^{7} 8$ prevents haemolysis. From these qualitative results it was concluded that the chrysotile fibres can adsorb phospholipids. It then became of interest to determine quantitatively the adsorption of pure phospholipids (PL) and to compare the result with the amount of PL adsorbed when chrysotile was exposed to red blood cell membranes. These investigations are the subject of the present paper.

Requests for reprints to: MC JAURAND, Laboratoire de Recherches sur les Affections Respiratoires et l'Environnement, Hôpital Henri Mondor, 51 Ave du Maréchal de Lattre de Tassigny, 94010 Créteil.

Supported by CRL, INSERM No 79.5.288.5.

Received 16 March 1979

Accepted 13 July 1979

\section{Material and methods}

All experiments were carried out with UICC A chrysotile. Suspensions of the fibres were obtained by ultrasonic treatment at $20 \mathrm{KHz}$, power: $20 \mathrm{~W}$ for $45 \mathrm{~s}$ in $\mathrm{KCl}-\mathrm{NaCl} 0 \cdot 145 \mathrm{M}$. Human RBC and RBC membranes (ghosts) were prepared as previously described. ${ }^{8}$ Liposomes were made of DPPC (Calbiochem): a suspension of DPPC $(15 \mu \mathrm{mole} / \mathrm{ml})$ was sonicated at $20 \mathrm{KHz}$, power: $20 \mathrm{~W}$, for $1 \mathrm{~min}$ in $\mathrm{KCl}-\mathrm{NaCl} 0 \cdot 145 \mathrm{M}$.

TREATMENT OF CHRYSOTILE

Aliquots of the suspension of chrysotile $(2 \mathrm{mg}$ for chemical analysis and $6 \mathrm{mg}$ for photoelectron spectrometry (XPS) analysis) were mixed with various amounts of liposomes ( 0 to $400 \mu \mathrm{g} / \mathrm{ml}$ of DPPC) or ghosts (0 to $200 \mu \mathrm{g} / \mathrm{ml}$ of phosphatides) to give a final concentration of chrysotile of $1 \mathrm{mg} / \mathrm{ml}$. The mixtures were then incubated for $15 \mathrm{~min}$ at $37^{\circ} \mathrm{C}$. Preliminary studies using a concentration of $500 \mu \mathrm{g}$ of DPPC per $\mathrm{ml}$ have shown that the equilibrium ratio of free DPPC to adsorbed DPPC occurs in the first minutes (table 1).

The separation of chrysotile from unadsorbed liposomes or ghosts was obtained by centrifugation 
Table 1 Kinetics of DPPC adsorption (XPS data)

\begin{tabular}{llll}
\hline Time & $M g_{2 s} / S i_{2 p}$ & $P_{2 p} / S i_{2 p}$ & $P_{2 p} / M g_{2 s}$ \\
\hline 0 & 0.83 & 0 & 0 \\
$30 \mathrm{~s}$ & 0.87 & 0.26 & 0.30 \\
$5 \mathrm{~min}$ & 0.87 & 0.27 & 0.31 \\
$15 \mathrm{~min}$ & 0.75 & 0.26 & 0.34 \\
\hline
\end{tabular}

in saccharose. The mixture of chrysotile-liposomes was placed on a $40 \%$ solution of saccharose and the mixture of chrysotile-ghosts was placed on a discontinuous saccharose gradient $(60 \%-40 \%)$; all the samples were spun for $20 \mathrm{~min}$ at $3000 \mathrm{rpm}$ $(1500 \mathrm{~g})$. It had previously been established that the chrysotile reaches the bottom of the tube, the unadsorbed liposomes are layered at the top of the saccharose solution, and the unadsorbed ghosts are at the interface $60 \%-40 \%$. The saccharose and the interfaces were then aspirated, and the chrysotile was washed three times in $\mathrm{KCl}-\mathrm{NaCl} 0 \cdot 145 \mathrm{M}$.

\section{LIPID EXTRACTION}

For the chemical analysis, the determination of the amount of PL adsorbed was conducted by analysis of the PL extracted from chrysotile fibres. The lipids were extracted for $5 \mathrm{~min}$ in $2 \mathrm{ml}$ chloroformmethanol mixture (vol/vol) and centrifuged. A second extraction was carried out for $5 \mathrm{~min}$ in $2 \mathrm{ml}$ of chloroform. Solvents were evaporated under pressure.

\section{DETERMINATION OF THE PL ADSORBED}

\section{Chemical analysis}

The dried extracts were mineralised with perchloric acid according to the method of Chen et al. ${ }^{9}$ Standard curves were obtained with DPPC (0-6 $\mu \mathrm{g}$ of phosphorus). The equilibrium concentration was determined from the difference between the concentration of PL in the solution before mixing with chrysotile and the concentration of PL adsorbed.

The results were expressed as $\mu \mathrm{g}$ of DPPC adsorbed for each $\mathrm{mg}$ of chrysotile, for experiments with liposomes; and as $\mu \mathrm{g}$ of phosphatide adsorbed (phosphorus concentration $\times 23.5$ ) for experiments with ghosts. To determine the amount of DPPC for liposomes, or phosphatides from ghosts preincubated with chrysotile, standard curves giving the amount of PL against the volume of liposomes or ghosts suspension were obtained. The liposomes $(10$ to $30 \mu \mathrm{l})$ were dissolved by the addition of ethanol and then evaporated before mineralisation. The ghosts (50 to $250 \mu 1,20 \%$ ghosts) were precipitated in $40 \% \mathrm{vol} / \mathrm{vol}$ trichloracetic acid. After centrifugation the pellet was mineralised.
Photoelectron spectrometry analysis

XPS or ESCA is a relatively new technique, which has been applied essentially to studying organic surfaces, and catalysis or chemisorption on metals. The study of silicate materials is being developed at present. In this field the most rewarding research has been in the use of the method for determining the surface composition of materials from the intensity of the peaks of different chemical elements. ${ }^{10-12}$ The XPS method measures the kinetic energy of photoelectrons ejected from a surface using soft $x$ rays; this method is sensitive to all elements of $Z>2$, with a limit of detection depending on the particular element measured.

The characteristics of the method are as follows: (1) the depth of investigation into the oxides and silicates is between 50 and $100 \AA{ }^{13}$ It is sufficient to provide data in volume, while still allowing surface analysis. (2) Measurements of the intensity of peaks is easily reproduced and is usually of a quality superior to $+10 \%$ providing that a ratio of concentration in a homogeneous material is determined. (3) It is a quantitative method providing it can be standardised on fresh breaks of homogeneous material of known composition. ${ }^{14}$ (4) The samples do not require any particular preparation. Cleavage faces, grains, and powders or mineral fibres may be analysed in the same way. The principles of the method, which have been applied in the mineralogical field, ${ }^{15}$ are described in the biological field by Millard and Bartholomew ${ }^{16}$ and Thomassin. ${ }^{17}$

The XPS analysis was performed on an AEI apparatus fitted with a magnesium anticathode (radiation $\mathrm{MgK} \alpha=1253.6 \mathrm{eV}$ ). Graphic recordings were used to measure the heights of peaks for $M_{2 s}\left(E_{B}=88.7 \mathrm{eV}\right), \operatorname{Si}_{2 p}\left(E_{B}=102.9 \mathrm{eV}\right), P_{2 p}$ $\left(E_{B}=133.9 \mathrm{eV}\right)$, and $N_{1 s}\left(E_{B}=399.8 \mathrm{eV}\right)$. The analysed area is about $50 \mathrm{~mm}^{2}$. It should be noted that for XPS the chrysotile surface is considered homogeneous.

For XPS analysis, batches of $6 \mathrm{mg}$ of chrysotile were treated as described above. After the separation of the excessed PL, the fibres were concentrated by filtration (Millipore, porosity $5 \mu \mathrm{m}$ ) and well rinsed with deionised water. Then the filter was cut to obtain the sample $(5 \mathrm{~mm} \times 15 \mathrm{~mm})$ that was stuck on the sample probe.

\section{Quantitative XPS analysis}

The counting rate in a photoelectron peak from an element is given by

$$
\mathrm{I}=\int_{0}^{\infty} \mathrm{dI}
$$

where

$$
\mathrm{dI}=\sigma \mathrm{FSNe}^{-\mathrm{y} / \lambda} \mathrm{dy}
$$


and $\sigma=$ cross section of the sublayer considered by X-rays,

$\mathrm{F}=\mathrm{X}$-rays flux,

$\mathbf{S}=$ constant of the apparatus,

$\mathrm{N}=$ atom number in the layer of dy thickness by unit volume,

$y=$ depth in the solid,

$\lambda=$ mean free path of electron.

In the case where $\mathrm{N}$ does not vary with the depth, equation (1) becomes

$$
\mathrm{I}=\sigma \mathrm{FS} \mathrm{N} \lambda .
$$

For example, applied respectively to magnesium and silicon, in the case of chrysotile, we obtain the following relation

$$
\mathrm{R}=\mathrm{I}_{\mathrm{Mg}} / \mathrm{I}_{\mathrm{Si}}=\sigma_{\mathrm{Mg}} / \sigma_{\mathrm{Si}} \cdot \mathbf{C}_{\mathrm{Mg}} / \mathrm{C}_{\mathrm{Si}}
$$

where $\mathrm{C}_{\mathrm{Si}}, \mathrm{C}_{\mathrm{Mg}}=$ concentrations within the outer $100 \AA$ in the solid.

Taking into account the very close values of the energies of the $\mathbf{M g}_{2 \mathrm{~s}}$ and $\mathrm{Si}_{2 \mathrm{p}}$ electrons, the terms $\lambda$ and $S$ in equation 3 cancel out and $F$ can be supposed constant during each analysis. (NB This relation shows that the theoretical slope of the calibration curves is then equal to the ratio of the cross-sections.)

DETERMINATION OF THE PROTEIN ADSORBED In some experiments with ghosts the amount of protein adsorbed was determined after solubilisation for 24 hours in $\mathrm{NaOH} 0.5 \mathrm{~N}$, using Lowry's procedure. ${ }^{18}$ Samples were centrifuged before the spectrophotometric measurement. It should be noted that the ghosts were not completely free of haemoglobin, but after incubation with the fibres and separation on saccharose haemoglobin stayed in the upper fraction.

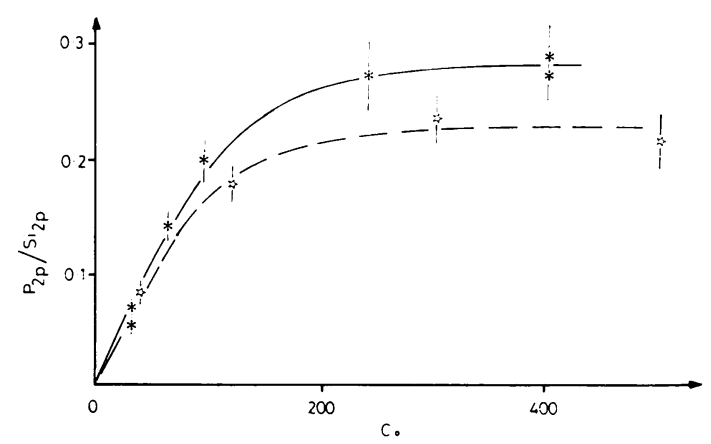

Fig 1 Adsorption isotherms for DPPC liposomes determined by XPS analysis. $c_{0}=D P P C$ initial concentration in $\mu \mathrm{g} / \mathrm{ml}$.

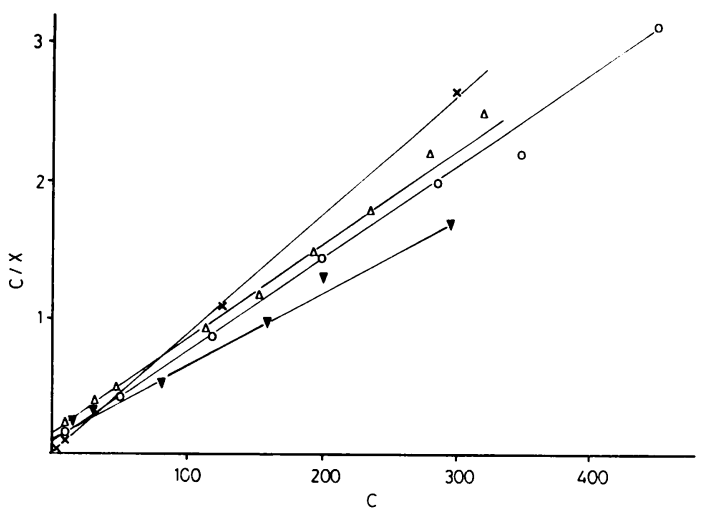

Fig 2 Plot of $c / x$ against $c$ for liposomes adsorption (chemical analysis). $c=$ equilibrium DPPC concentration in $\mu \mathrm{g} / \mathrm{ml} ; x=\mu g$ of DPPC adsorbed $/ \mathrm{mg}$ of chrysotile.

\section{Results}

\section{LIPOSOME ADSORPTION}

Adsorption isotherms for DPPC are shown in figs 1 and 2. In fig 1 the adsorption of PL was characterised by means of the evolution of the peak ratio $\mathbf{P}_{2 p} / S_{2}$ related to the initial DPPC concentration. With chemical analysis, a plateau was obtained for an initial concentration of DPPC around $200 \mu \mathrm{g} / \mathrm{ml}$. Figure 2 shows the variation of the amount of DPPC adsorbed, $\mathrm{x}(\mu \mathrm{g} / \mathrm{mg}$ of chrysotile) versus the equilibrium concentration $c$ of DPPC, expressed by a plot of $\mathrm{c} / \mathrm{x}$ against $\mathrm{c}$, which approximates closely to a straight line. From such isotherms, it is possible to deduce the maximum capacity, $\mathbf{x}_{0}$, of the chrysotile fibres, when $c \rightarrow \infty$. From five experiments, the results have shown that for each $\mathrm{mg}$ of chrysotile, $\mathrm{x}_{0}=155 \pm 27 \mu \mathrm{g}$. Assuming that this plateau corresponds to a total coverage of chrysotile surface by liposomes, a cross sectional area (s) of one molecule of DPPC at the PL-chrysotile interface may be deduced.

If DPPC are adsorbed in bilayer, the expressions for the photoelectron peak intensities can be deduced as follows.

(a) For phosphorus two contributions must be taken into account, the outer atoms and the atoms at the interface chrysotile-bilayer. The intensity of the peak can be expressed by the following expression:

$$
I_{p}=\sigma_{p} F S_{p} N_{p} \theta\left(1+e^{-1 / \lambda^{\prime}}\right)
$$

where $\mathrm{N}_{\mathrm{p}}=$ number of phosphorus atoms at the interface per unit area,

$$
1=\text { thickness of the bilayer, }
$$




$$
\begin{aligned}
\lambda^{\prime} & =\text { mean free path of } P_{2 p} \text { electrons through } \\
& \text { the PL layer, and } \\
\theta= & \text { surface coverage. }
\end{aligned}
$$

(b) The intensity of the $\mathrm{Si}_{2 p}$ photoelectron peak can be expressed as:

$$
\mathrm{I}_{\mathrm{Si}}=\sigma_{\mathrm{Si}} \mathrm{F} \mathrm{S}_{\mathrm{Si}} \mathrm{C}_{\mathrm{Si}} \lambda\left(1-\theta+\theta \mathrm{e}^{-1 / \lambda^{\prime}}\right)
$$

where $\lambda=$ mean free path of $\mathrm{Si}_{2 p}$ electrons in the chrysotile which has a value around $20 \AA-25 \AA$, and

$\mathrm{C}_{\mathrm{Si}}=$ silicon atom number by unit volume: $(1 \cdot 15) 10^{-2} / \AA^{3}$.

Then, the peak ratio is:

$$
\mathbf{R} \theta=\frac{\mathbf{I}_{\mathrm{P}}}{\mathbf{I}_{\mathrm{Si}}}=\frac{\sigma_{\mathrm{P}}}{\sigma_{\mathrm{Si}}} \frac{\mathrm{N}_{\mathrm{P}}}{\mathbf{C}_{\mathrm{Si}} \lambda} \frac{\theta\left(1+\mathrm{e}^{-1 / \lambda^{\prime}}\right)}{1-\theta+\theta \mathrm{e}^{-1 / \lambda^{\prime}}}
$$

Let $\rho=\frac{\mathrm{I}_{\mathrm{Si}}(\theta=1)}{\mathrm{I}_{\mathrm{Si}}(\theta=0)}$, then we have $\rho=\mathrm{e}^{-1 / \lambda}$.

For a total surface coverage, $\theta=1$, and $\mathbf{R} \theta$ becomes:

$$
\mathrm{R}_{1}=\frac{\sigma_{\mathrm{P}}}{\sigma_{\mathrm{Si}}} \frac{\mathrm{N}_{\mathrm{P}}}{\mathrm{C}_{\mathrm{Si}} \lambda} \frac{1+\rho}{\rho} .
$$

Using the absolute heights of peaks, an approximate value of $\rho$ can be obtained as $\rho \simeq 0.43$ and $R_{1} \simeq 0.26$. Taking $\lambda_{\mathrm{Si}}=25 \AA$, the occupation of one molecule of DPPC is $\mathrm{s}=\frac{1}{\mathrm{~N}_{\mathrm{P}}}=64 \AA^{2}$, and if $\lambda_{\mathrm{Si}}=20 \AA$, then $s=80 \AA^{2}$. This value is very close to the values obtained by Lecuyer and Dervichian ${ }^{19}$ using lecithin, who found that the mean area may be from 65 to $55 \AA^{2}$, depending on the water content.

When the same calculation was made assuming that DPPC were adsorbed in monolayers the results showed that $\mathrm{s}=24 \AA^{2}$ with $\lambda_{\mathrm{SI}}=20 \AA$, and $\mathrm{s}=19 \AA^{2}$ when $\lambda_{\mathrm{Si}}=25 \AA$.

By chemical analysis the available surface area of chrysotile could be estimated, assuming that the cross-sectional area of one molecule of DPPC is $60 \AA^{2}$ and that DPPC are adsorbed in bilayer. The mean available surface area is $38+6.7 \mathrm{~m}^{2} / \mathrm{g}$ (range 44.4 to $27.5 \mathrm{~m}^{2} \mathrm{~g}$ ).

The adsorption coefficient can be deduced from the relation $\theta=\operatorname{Kc}(1-\theta)$. The mean value of four experiments is $0.044 \mathrm{ml} / \mu \mathrm{g}$ (chrysotile concentration: $1 \mathrm{mg} / \mathrm{ml}$ ) corresponding to a $50 \%$ coverage at $23 \mu \mathrm{g} / \mathrm{ml}$. Surprisingly, this parameter varies with the chrysotile concentration; this is referred to again in the discussion.

\section{GHOST ADSORPTION}

From chemical analysis, it appears that ghost adsorption is biphasic (fig 3). Maximal adsorption cannot be deduced from the representation of $c / x$

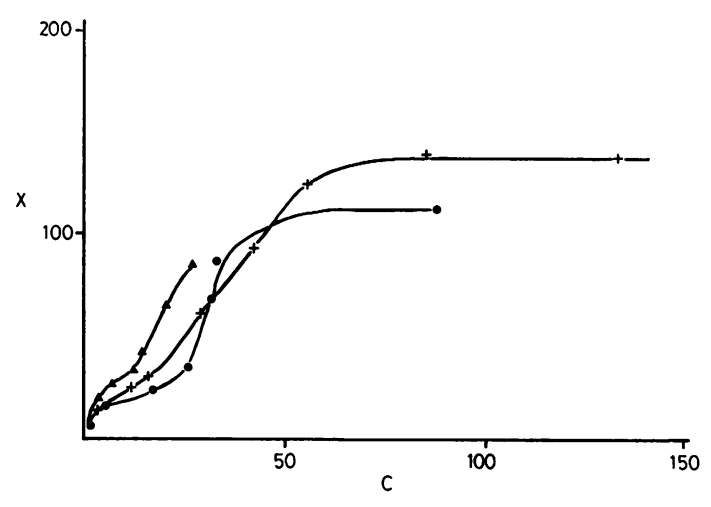

Fig 3 Adsorption isotherms for ghosts obtained by chemical analysis. $c=P L$ concentration in $\mu \mathrm{g} / \mathrm{ml}$; $x=\mu g$ of $P L$ adsorbed/mg of chrysotile.

against $\mathrm{c}$. If it is postulated that the value obtained at the plateau gives roughly the maximal adsorption, it is possible to estimate the surface coverage, $\theta$. A $50 \%$ coverage is obtained for $\mathrm{c} \simeq 25 \mu \mathrm{g} / \mathrm{ml}$. Two experiments were carried out in order to assay both proteins and PL adsorbed on to the fibres. The measurements were performed at various initial concentrations of ghosts. The ratio $\mathrm{r}=\mu \mathrm{g}$ of protein adsorbed: $\mu \mathrm{g}$ of PL adsorbed was calculated and compared to that obtained for ghosts, without fibres, obtained at the interface after centrifugation on saccharose. The results showed that $r$ was nearly constant when the amount of ghosts was increased (table 2).

The results obtained by XPS analysis have shown (figs 4 and 5) variations from one experiment to another. The ratios $\mathbf{P}_{2 p} / \mathrm{Si}_{2 p}$ and $\mathrm{N}_{1 \mathrm{~s}} / \mathrm{Si}_{2 p}$ have been plotted as a function of PL concentration. Actually, it is not possible to elaborate a simple model to explain the data. The intensity of the photoelectron peak $\mathrm{N}_{1 \mathrm{~s}}$, however, indicates that both proteins and PL must be adsorbed on chrysotile fibres.

Table 2 Proportions of proteins and PL adsorbed on to chrysotile fibres

\begin{tabular}{clll}
\hline Ghosts $^{*}$ & $r \dagger$ & Ghost & $\begin{array}{l}r \dagger \\
1 \cdot 7 \ddagger\end{array}$ \\
\hline $5 \cdot 5$ & $1 \cdot 5 \ddagger$ & & $2 \cdot 5$ \\
11 & $1 \cdot 7$ & 27 & $1 \cdot 8$ \\
22 & $1 \cdot 7$ & 53 & $1 \cdot 5$ \\
33 & $1 \cdot 8$ & 80 & 1.6 \\
44 & $2 \cdot 2$ & 107 & 1.6 \\
55 & 1.8 & 160 & 1.7 \\
85 & $2 \cdot 1$ & 214 & $2 \cdot 4$ \\
111 & $1 \cdot 8$ & 267 & \\
\hline
\end{tabular}

*Initial concentration in ghosts measured as $\mu \mathrm{g} \mathrm{PL/ml.}$ $\dagger \mu g$ protein adsorbed: $\mu \mathrm{g}$ PL adsorbed. $\ddagger$ Ratio at interface. See text for explanation. 


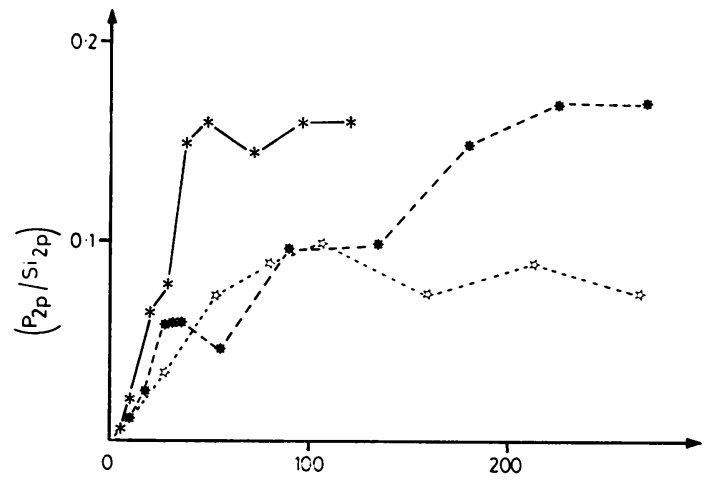

Fig 4 Adsorption isotherms for ghosts obtained by $X P S$ analysis. Variation of $R=P_{2 p} / S i_{2} p$ with initial concentration in DPPC $(\mu \mathrm{g} / \mathrm{ml})$.

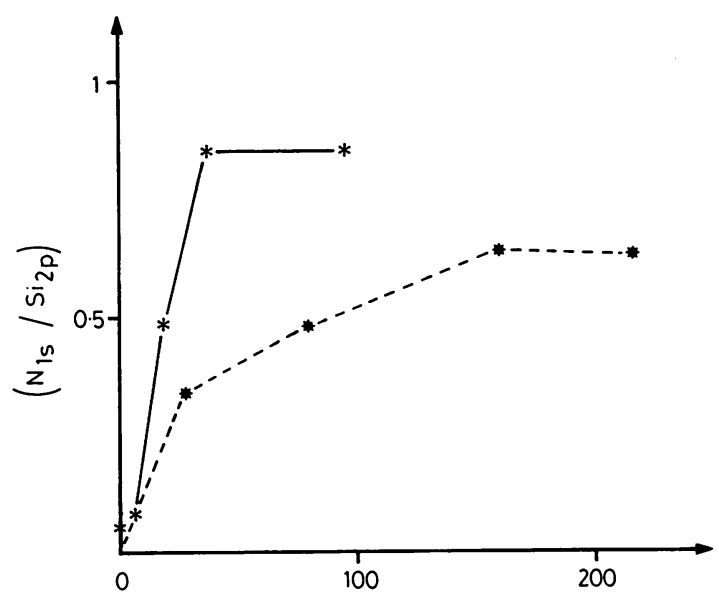

Fig 5 Adsorption isotherms for ghosts obtained by $X P S$ analysis. Variation of $R=N_{1} / S i_{2 p}$ with initial concentration in DPPC $(\mu \mathrm{g} / \mathrm{ml})$.

\section{Discussion}

The differences observed from one experiment to another may indicate that the available surface area for DPPC or ghost adsorption is not constant for each milligram of chrysotile, but depends on the degree of opening of the fibres. Indeed, in each experiment the sonication was made in the same conditions, but the sample, before being sonicated, may be more or less aggregated. Moreover, adsorption of membranes is complex because it must concern glycoproteins, proteins, and lipids; the preparation of erythrocyte ghosts may produce inside-out ghosts, so that either the inner or the outer membrane may be exposed; the large variations in results for different experiments may arise from the complex components or from the heterogeneous ghosts.

The results show that the shape of isotherms obtained for DPPC and ghosts are different, however, both are Langmuirian, using the classification of Giles et al. ${ }^{20}$ At maximum surface coverage, DPPC are adsorbed in bilayer; this occurs probably at low concentration because of the shape of the isotherm; in the case of ghosts the adsorption is more complex as shown by the isotherms.

The representation of $\theta$ with the two methods of analysis ${ }^{21}$ seems to indicate a higher surface coverage by XPS analysis. This fact may be explained by a variation of the available surface of chrysotile when this mineral is in contact with a dispersing agent such as DPPC. In the case of XPS, the formulation of $\theta$ is independent of the available surface. For chemical analysis, the expression of $\theta$ is obtained assuming the constancy of the available surface. This hypothesis is confirmed by the fact that the available surface calculated at the plateau value $\left(38 \mathrm{~m}^{2} / \mathrm{g}\right)$ is higher than the specific surface area measured by BET $\left(20 \mathrm{~m}^{2} / \mathrm{g}\right)$.

Elsewhere, an enhancement $(1.2 \mathrm{ev})$ of the kinetic energy of $\mathrm{Si}_{2 p}$ and $\mathbf{M g}_{2 \mathrm{~s}}$ electrons was observed when the degree of surface coverage by DPPC increased. This indicates a modification of the electrical charge of the mineral surface: the surface of chrysotile seems positively charged on the uncovered samples and the DPPC adsorption decreases the surface charge. These results are in good agreement with the measurement of zeta potential performed by Light and Wei. ${ }^{6}$

From these experiments, it was difficult to appreciate the affinity of PL for chrysotile, because of the variations from one experiment to another. When the adsorption of liposomes was studied, however, a value of $\mathrm{K}$ of $0.044 \mathrm{ml} / \mu \mathrm{g}$ was obtained; these experiments were carried out with a chrysotile concentration of $1 \mathrm{mg} / \mathrm{ml}$. When the experiments were performed with chrysotile at a concentration of $2 \mathrm{mg} / \mathrm{ml}$, the value of $\mathrm{K}$ was $0.017 \mu \mathrm{l} / \mathrm{mg}$, but maximal adsorption was nearly constant $(208 \mu \mathrm{g}$ for each $\mathrm{mg}$ of chrysotile). Furthermore, when the amount of DPPC adsorbed was expressed against concentration of DPPC in mg of DPPC for each $\mathrm{mg}$ of chrysotile, it appears that the curves may be superimposed. It must be noted, however, that $50 \%$ surface coverage was obtained at about $25 \mu \mathrm{g} / \mathrm{ml}$ of PL, either with liposomes or ghosts. These results may be due to the high concentration of DPPC, since the formula for adsorption is known for dilute solution. Moreover, DPPC in liposomes as well as in ghosts are engaged in definite structures, and the mechanism must be different from isolated molecules. 
It is noteworthy that the maximum capacity of chrysotile fibres of $155+27 \mu \mathrm{g} / \mathrm{mg}$ agrees closely with results obtained by Desai and Richards ${ }^{4}$ with pulmonary surfactant; indeed, pulmonary surfactant contains mainly DPPC. ${ }^{22}$

If we now refer to previous experiments on the inhibition of haemolysis by liposomes or ghosts ${ }^{8}$ it appears that a good correlation may be observed. With liposomes an $80 \%$ inhibition of haemolysis was observed when chrysotile was pretreated with about $0.25 \mathrm{mg}$ of DPPC for each $\mathrm{mg}$ of the fibres. In the present experiments, when $\theta=0 \cdot 8$, the initial concentration of DPPC was $0.22 \mathrm{mg}$ for each $\mathrm{mg}$ of chrysotile. In the same way, with regard to the ghosts, $100 \%$ of inhibition was obtained at a ratio of 0.20 (mg of lipids per $\mathrm{mg}$ of chrysotile), which is equivalent to $0.12 \mathrm{mg}$ of phosphatides; in the present experiments $\theta=1$ for a ratio of $0 \cdot 20$ to $0 \cdot 13$.

From these results, and those of other workers, it appears that membranes either natural or model can be adsorbed on to chrysotile fibres. A mechanism for haemolysis was suggested by Harington et $a^{23}$ and Allison. ${ }^{24}$ Harington et $a^{23}$ have shown that the interaction with membrane sialoglycoproteins is responsible for haemolysis. Allison ${ }^{24}$ suggested that such proteins then form a cluster that could create channels through which small molecules move; then a Donnan equilibrium occurs and causes the RBC to burst. The most likely explanation, however, of chrysotile haemolysis appears to be that if the interaction with RBC is due to electrostatic forces ${ }^{23}$ it may be followed by an adsorption of phospholipids with concomitant release of haemoglobin and adsorption of the whole membrane. Then the fibres become unreactive owing to their covering by membranes, explaining why the kinetics are selfinhibiting.

\section{References}

1 Jones BM, Edwards JH, Wagner JC. Adsorption of serum proteins by inorganic dusts. Br J Ind Med 1972;29:287-92.

${ }^{2}$ Morgan A. Adsorption of human serum albumin by asbestiform minerals and its application to the measurement of surface areas of dispersed samples of chrysotile. Environ Res 1974;7:330-41.

${ }^{3}$ Ralston J, Kitchener JA. The surface chemistry of amosite asbestos and amphibole silicate. Environ Res 1975;50: 242-9.

4 Desai R, Richards RJ. The adsorption of biological macromolecules by mineral dusts. Environ Res 1978; $16: 449-64$.
${ }^{5}$ Light WG, Wei ET. Surface charge and asbestos toxicity. Nature 1977;26:537-9.

- Light WG, Wei ET. Surface charge and haemolytic activity of asbestos. Environ Res $1977 ; 13: 135-45$.

' Desai R, Hext P, Richards R. The prevention of asbestosinduced hemolysis. Life Sciences 1975;16:1931-8.

8 Jaurand MC, Magne L, Bignon J. Phospholipids protect red blood cells from haemolytic action of asbestos. Br J Ind Med 1979;36:113-6.

${ }^{9}$ Chen PS, Toribara TY, Warner H. Micro determination of phosphorus. Anal Chem 1956;28:1756-8.

${ }^{10}$ Escard JH, Brion DJ. Study of composition of leached glass surface by photoelectron spectroscopy. J Am Ceram Soc 1975;58:269-99.

11 Thomassin JH, Touray JC, Trichet J. Etude par spectrométrie ESCA des premiers stades d'altération d'une obsidienn:: le comportement relatif de l'aluminium et du silicium. CR Acad Sci Paris 1976;282, série D:1229-32.

12 Tempere JF, Delafosse D, Contour JP. An $x$-ray photoelectron study on zeolites. Chem Phys Lett 1975;33:95-8.

${ }^{13}$ Riggs WM, Parker MJ. Surface analysis by $x$-ray photoelectron spectroscopy. In: Czanderna AW ed. Methods and phenomena 1. Amsterdam, Oxford, New York: Elsevier, 1975:103-59.

14 Carter MJ, Schweitzer GK, Carlson TA. Experimental evaluation of a simple model for quantitative analysis in $x$-ray photoelectron spectrometry. J Electr Spectr Relat Phenom 1974;5:827-35.

15 Petrovic R, Berner RA, Goldhaber MB. Rate control in dissolution of alkali feldspars. Geochem Cosmochim Acta 1976;40:537-48.

${ }^{16}$ Millard MM, Bartholomew JC. Surface studies of mammalian cells grown in culture by $x$-ray photoelectron spectroscopy. Anal Chem 1977;9:1290-6.

17 Thomassin JH. Apport de la spectrométrie de photoélectrons (XPS) à la cinétique géochimique. Etude de la dissolution de quelques silicates magnésiens (Forstérite, talc, chrysotile). Université d'Orléans: 1977. (Thèse de 3ème cycle.)

${ }^{18}$ Lowry OH, Rosebrough NJ, Farr AL, Randall RJ. Protein measurement with the Folin phenol reagent. J Biol Chem 1951;193:265-75.

19 Lecuyer H, Dervichian DG. Structure of aqueous mixtures of lecithin and cholesterol. J Mol Biol 1969;45:39-57.

20 Giles CH, Mac Ewan TH, Nakhawa SN, Smith D. Studies in adsorption. Part XI. A system of classification of solution adsorption isotherms, and its use in diagnosis of adsorption mechanisms and in measurement of specific surface areas of solids. J Chem Soc 1960:3973-93.

21 Jaurand MC, Thomassin JH, Magne, L Baillif P. Etude de l'adsorption des phospholipides par les fibres de chrysotile: confrontation des données de l'analyse chimique et de la spectrométrie de photoélectrons. CR Acad Sci Paris 1979;288:279-82.

${ }^{22}$ Harwood JL, Desai R, Hext P, Tetley T, Richards R. Characterization of pulmonary surfactant from ox, rabbit, rat and sheep. Biochem J 1975;151:707-14.

${ }^{23}$ Harington JS, Miller K, Macnab G. Hemolysis by asbestos. Environ Res 1971;4:95-117.

${ }^{24}$ Allison AC. Experimental methods. Cell and tissue culture: effects of asbestos particles on macrophages, mesothelial cells and fibroblasts. In: Bogovski P, Gibson JC, Timbrell V, Wagner JC, eds. Biological effects of asbestos. Lyon: IARC, 1973:89-93. 